\title{
How to Form a Bounding Arc Flash Study for Your Site
}

\author{
Michelle Palizzi \\ IEEE Member \\ Bechtel Nevada \\ P.O. Box 98521 \\ Las Vegas, NV 89193-8521
}

\author{
Sunil Kabra \\ Bechtel Power Corporation \\ 105 Green Fern Street \\ Madison, AL 35758
}

\begin{abstract}
This paper presents the concept, design, implementation and application of an original bounding study for arc flash. A bounding arc flash study, which is defined and bound by the characteristics of a particular site or plant, defines arc flash guidelines for electrical workers when the traditional method of calculation outlined in IEEE 1584 is inconvenient to use. The NFPA 70E offers default values in tables that are often used when a traditional study has not been achieved; however, these tables are not representative of all situations common to the workplace. The bounding arc flash study described is primarily designed for temporary power installations and for plants or sites that have not collected the data required by traditional methods. The design of the study is discussed in length so the process can be duplicated with specific adjustments required for your site or plant. Within the study, a typical range of equipment types is identified and then tested against an array of input data, such as short circuit levels, voltage levels, protective device settings, transformer sizes, cable lengths and emergency generation design. The paper explains how new developments affect this type of study and how to update accordingly.
\end{abstract}

Keywords - bounding arc flash study, personal protective clothing/equipment, arc flash, electrical safety, electrical hazards, industrial plants

\section{INTRODUCTION}

Arc flash hazards have been recognized by the industry for a relatively long time, however methods for quantifying this type of hazard have not been available until recently. An arc flash is the culmination of the circuit impedance allowing a current that exceeds the glow-to-arc transition current, so that a disruptive discharge occurs through air or over the surface of solid or liquid insulation, between parts of different potential or polarity, produced by the application of voltage wherein the breakdown path becomes sufficiently ionized to maintain an electric current. The total injury potential to personnel is not yet known but at least IEEE 1584-2002 permits the incident energy level to be calculated by the best-known technology. An enormous effort has taken place recently to test and quantify the arc flash hazard so safe recommendations can be adopted in the workplace. IEEE $1584-2002$ outlines a method of analysis, based on empirical data gathered from testing for affects of arcs-in-boxes and theoretical formulas for affects of arcs in open air, to be used by electrical engineers to make specific recommendations for each piece of equipment that may promote a hazard on the electrical system. In order to complete this type of study the electrical system under analysis must be modeled very accurately. This includes modeling detailed information such as cable size and length, overcurrent protection with device information including manufacturer, type, size and settings, and accurate information about loads, transformers and generation plus electrical configuration. IEEE 1584-2002 calculators and formulas cannot be utilized to determine incident energy at working distance and arc flash boundary without this information. The NFPA $70 \mathrm{E}-2004$ offers default values that are often used when a traditional study has not been achieved, however, the guidelines outlined in the standard are not representative of all situations common to the workplace. For instance, there may be $240 \mathrm{~V}$ devices on a particular system that will not clear within 2 cycles as required by the NFPA 70E - 2004 Table $130.7(\mathrm{C})(9)(\mathrm{a})$.

As a solution, a method of forming a bounding arc flash study for a site was derived and tested at a sample site with the intent of creating a method of identifying arc flash requirements either accurately or conservatively given the difficulty associated with calculating these requirements in a traditional way. The design of the study is discussed in length so the process can be duplicated with specific adjustments required for a particular site or plant. This method of performing arc flash analysis is primarily designed to help companies who must identify arc flash hazards for temporary installations or require a guideline until they have collected the data required for a more traditional study. Small companies and private contractors may also see a benefit in performing a bounding study rather than the traditional study outlined by IEEE 1584 - 2002. The bounding arc flash study heavily relies on the IEEE 1584 and NFPA 70E for its empirical data and theoretical formulas. 


\section{PURPOSE AND OBJECTIVE OF STUDY}

The purpose and objective of a bounding arc flash study is to establish the Personal Protective Clothing and/or Equipment (PPC/E) and Arc Flash Boundary requirements for the purpose of reducing the risk of arc flash hazards at your site. The study determines values for $\mathrm{PPC} / \mathrm{E}$, arc flash boundary and incident energy for a typical range of equipment types which are identified and then tested against an array of input data, such as short circuit levels, voltage levels, protective device settings, transformer sizes, cable lengths and emergency generation design. These values, illustrated by a chart, are designed for use in the field, to be used by a qualified electrical worker.

\section{METHODOLOGY AND ASSUMPTIONS}

The tables in NFPA 70E - 2004 make clear several characteristics of an arc flash hazard. For instance, it discusses how a particular task can be more hazardous than another task. This particular characteristic has been discussed at length at conferences and among industry specialists and may have some room for improvement. For instance, it may be argued that switching on a circuit breaker with a cover on may in some instances be just as harmful as switching a circuit breaker with a cover off because the cover may become a projectile object during an event and cause serious harm to the worker. For the purposes of this study it is recommended that a higher precaution be used for tasks that are rated very high by the table. Other tasks are not considered to have an individual risk associated with them by the bounding study and are instead analyzed according to equations outlined in IEEE $1584-2002$.

The tables of NFPA 70E also assign a level 0 or 1 PPC/E risk category for $240 \mathrm{~V}$ applications and below. According to the IEEE 1584 Working Group, testing is not yet certain about the hazards at $240 \mathrm{~V}$ and below. While considerably less dangerous in most cases, there are instances where a high arcing current can occur and create a potentially high hazard. As pointed out in IEEE $1584-2002$ these low voltages should be examined when it involves at least one $125 \mathrm{kVA}$ or larger low-impedance transformer in its immediate power supply. In this case an additional safety factor is recommended.

Other characteristics are made clear by the notes assigned to the tables in the NFPA 70E standard. Short circuit values or clearing times, when exceeding a certain value, pose a high risk and users are cautioned not to use the tables in this particular case, however, there is no alternative offered by the standard. Also, an arc flash boundary default value of $4.0 \mathrm{ft}$ is given for applications $600 \mathrm{~V}$ and below, but is recommended for devices that operate at a product of 6 cycles ( 0.1 seconds) and 50kA or any combination not exceeding 300 . If you consider devices that clear at a product of 6 cycles and 50kA or any other combination less than 300 in the IEEE $1584-2002$ Calculator the outcome will typically be a PPC/E of 2 or 3 with a distance above 4.0 feet. Since the IEEE $1584-2002$ is more conservative it is used in the bounding arc flash study to determine default values for applications $600 \mathrm{~V}$ and below and $1 \mathrm{kV}$ and above. Default arc flash boundaries are determined best by considering an array of devices under various conditions in the IEEE 1584 - 2002 Calculator and trending the results. The first step is to assign PPC/E categories for a given device and a set of conditions. The second step is to determine the required arc flash boundary and incident energy level for each PPC/E category.

Several characteristics of an arc flash hazard are also pointed out by the text and equations contained in the IEEE $1584-2002$ standard. For instance, the following variables all have an affect on the outcome of the assigned PPC/E level, arc flash boundary and incident energy level for a particular device within the given system: bolted fault current, motor contribution, voltage level, trip and opening time of the protection device at the calculated arcing current, enclosure type, grounding configuration and working distance. Of course, fault current level is dependent on overall system design and operating configuration and trip and clearing times are dependent on the specifications of the protective device in question.

The overall method for developing a default system study for a site is to devise a comprehensive list of devices that envelop a range of clearing and trip times for the site and to consider these devices against an array of input data, such as short circuit levels, voltage levels and protective device settings. The desired outcome is to develop categories of equipment at each voltage with assigned $\mathrm{PPC} / \mathrm{E}$ levels under various conditions. For each PPC/E level there shall be assigned an arc flash boundary based on the greatest distance dictated by the trending.

To determine PPC/E levels the IEEE 1584 - 2002 Calculator must be used. It is assumed that not enough system data is available to complete a short circuit study. Assumptions that may have been made for your site to complete a system fault study may be invalid for the purposes of arc flash, therefore, making the study itself invalid for determining arc flash requirements. Arcing current which is directly linked to the voltage can be less than half the value of the bolted fault current. Under these conditions it is important that the arcing current not be too low to prevent tripping of the device during an event. This can be an extremely hazardous condition. On the 
other hand, if the arcing current is too high the hazard can also become very dangerous. The bounding calculation is primarily designed for a system where a precise short circuit study is not available. A range of short circuit levels should be selected for the site. For instance, typical facility loads in a rural area will provide low fault levels that should be considered for contributing to low arcing currents. Large industrial motor loads and generators in a plant can contribute to high fault levels and should also be considered for contributing to high arcing currents. There should be enough information available to develop a range of fault levels for your site. For the sample study a range of short circuit values between $1 \mathrm{kA}$ and $40 \mathrm{kA}$ was considered. For large industrial loads or ranges beyond 40kA, identify these higher short circuit areas as hazardous by area and include that in the results section of the study.

There are distinctive cases that may fall outside of the typical range of short circuit values or be more hazardous for a variety of reasons. In these cases the default values for PPC/E category and arc flash boundary should be at a maximum. One of these cases is when the main source of power is an emergency or backup generator. The older equipment, which is common at many plants and sites, can be unpredictable. The older generators are often protected with devices that are set high, if protected at all, which allows roughly $200 \%$ of the full load current to pass through to devices fed from the generator. This means the generator will not trip off-line during low level faults. Since an arcing current often has the same characteristics as a low level fault it can be extremely hazardous to work on an energized device that is fed from the generator because it will not trip and the arc will not be extinguished by the protective device in a reasonable amount of time, if at all.

The assumptions made by the bounding study will be unique to the site and are vital to the outcome of your calculation. If all of the devices are solidly grounded, consider this an assumption of the calculation. When this information in unknown, an ungrounded configuration should be assumed since it is the worst-case scenario. The trip time and opening time of the devices should be limited to 2 seconds. This limitation is due to the fact that either a worker will move away from the event or be forced away by the blast in this amount of time. Workers should avoid working on energized equipment in tight spaces where they cannot move from the blast area. If working in a tight area maximum PPC/E clothing should be worn. The type of enclosure, or equipment class, may be assumed conservatively for the devices. For the sample study all devices were assumed to be in either motor control center (MCC), panelboard or switchgear type enclosures. These scenarios are considered to envelop the open air and cable configurations, which are generally not as common, since the results are more conservative.

Assumptions may also be required for various devices on your system. For instance, in the sample study, devices controlled by a variety of tripping devices were considered. One way to categorize the hazards associated with each type of tripping device is to consider various risks for several ranges of settings. This would require an individual to consider the settings before determining the arc flash risk associated with their work. This is because the settings of any type of tripping device can have a profound affect on the time-current characteristics of the device, which significantly alter the opening and trip times of the device. Since these times are so important to the outcome it is important to be both realistic and conservative. For the sample study devices controlled by relays and by electronic trip units (ETUs) were considered. If possible each device must first be categorized and trended by its settings. Since the sample site had a vast number of relay types with various types of settings, the possible combinations available were beyond reason. As a result a default $\mathrm{PPC} / \mathrm{E}$ value of 4 for all work associated with a device controlled by a relay was recommended. It is recommended that relay controlled devices be considered for analysis. This requires that a list of the relays be developed and categorized effectively. This methodology was applied for the ETUs at the sample site and a similar method can be applied to devices controlled by relays at any site.

To devise a list of ETUs for analysis many trip units with various plug sizes should be considered. The plug size, not the frame size, is one of the main timecurrent characteristics of this type of device. ETUs without an instantaneous or short-time feature (LS and LI type) should be considered separately from the LSI type units. The long-time delay and long-time pickup settings should be set high. An exhaustive list of LSI type ETUs was included in the sample bounding study since the sample site had installed only LSI type breakers.

The devices listed for testing should be considered at the appropriate voltage (e.g., $480 \mathrm{~V}, 4160 \mathrm{~V}$ ) in the IEEE $1584-2002$ Calculator. For the purpose of the sample study the following configurations were considered:

$480 \mathrm{~V}$, switchgear, bolted fault current $=1 \mathrm{kA}$

$480 \mathrm{~V}$, switchgear, bolted fault current $=5 \mathrm{kA}$

$480 \mathrm{~V}$, switchgear, bolted fault current $=15 \mathrm{kA}$

$480 \mathrm{~V}$, switchgear, bolted fault current $=30 \mathrm{kA}$

$480 \mathrm{~V}$, switchgear, bolted fault current $=40 \mathrm{kA}$

$480 \mathrm{~V}, \mathrm{MCC} /$ panel, bolted fault current $=1 \mathrm{kA}$ 
$480 \mathrm{~V}, \mathrm{MCC} /$ panel, bolted fault current $=5 \mathrm{kA}$ $480 \mathrm{~V}, \mathrm{MCC} /$ panel, bolted fault current $=15 \mathrm{kA}$ $480 \mathrm{~V}, \mathrm{MCC} /$ panel, bolted fault current $=30 \mathrm{kA}$ $480 \mathrm{~V}, \mathrm{MCC} / \mathrm{panel}$, bolted fault current $=40 \mathrm{kA}$ 4160 , switchgear, bolted fault current $=1 \mathrm{kA}$ 4160 , switchgear, bolted fault current $=5 \mathrm{kA}$ 4160 , switchgear, bolted fault current $=15 \mathrm{kA}$ 4160 , switchgear, bolted fault current $=30 \mathrm{kA}$ 4160 , switchgear, bolted fault current $=40 \mathrm{kA}$

Motor contribution can be included in the selected range of fault currents as done in the sample study, so it is not required as a separate and variable input during the calculation stage. All devices were considered solidly grounded since all devices are configured this way at the sample site. Each device was modeled on a time-current curve (TCC), including the circuit breakers controlled by the ETUs. Each ETU was modeled under the following four conditions:

(1) short-time pickup = highest setting

short-time delay $=0.3$

instantaneous $=4$

(2) short-time pickup $=$ highest setting

short-time delay $=0.3$

instantaneous $=6$

(3) short-time pickup = highest setting

short-time delay $=0.3$

instantaneous $=10$

(4) short-time pickup $=4$

short-time delay $=0.3$

instantaneous $=$ highest setting

These settings were selected as possible break points after reviewing the time-current characteristics with many setting changes against the arcing currents determined by the configurations and bolted fault currents listed above.

\section{IEEE 1584 - 2002 CALCULATOR}

An array of voltages, fault levels, device size, device type and device settings, equipment class and grounding configurations, as described above, are the required input for the IEEE 1584 - 2002 Calculator. This input is required entry in the columns on the "Data Normal" Sheet of the Excel based program. A range of bolted fault currents (Column $\mathrm{C}$ ) has been selected as input since a specific model is not available. Since this range is inclusive of the motor contribution, the motor contribution entered into the calculator is zero. The voltage (Column B), working distance (Column L), equipment class (Column M) and grounding type (Column N) should all be specified. The arcing current and reduced arcing currents are calculated from this data and displayed in Columns F and I. A list of devices has been selected for testing and should envelop the types of devices at your site. In Column $\mathrm{O}$ the protective device type should be specified as " 0 " for general. Once the TCC curves have been obtained, the opening and clearing times at the arcing current levels (Column F) and reduced arcing current levels (Column I) for each device can be entered into the calculator. The required output from the calculator is the $\mathrm{PPC} / \mathrm{E}$ category and arc flash boundary.

\section{TRENDS FOR PPC/E}

The output from the calculator must be organized for the purpose of trending the output data and determining the appropriate PPC/E category. In the sample study two main tables were created. The first table (see Table 1) had each $4160 \mathrm{~V}$ device assigned to a row, from smallest size to largest size (according to trip or plug value). Five columns were provided for each input fault current level ( $1 \mathrm{kA}, 5 \mathrm{kA}$, etc.) and the table shows the worst-case $\mathrm{PPC} / \mathrm{E}$ and arc flash boundary on the given matrix. The second table (see Table 2) was designed in a similar manner for $480 \mathrm{~V}$ devices. Since the circuit breakers controlled by the ETUs are installed at $480 \mathrm{~V}$ at the sample site it was important to compare these results by giving each group of settings a unique row, yet next to each other for easy comparison.

Notes from the first table are taken down for each device, such as "PPC/E $=1$ or less under all conditions" or "200A fuses require $\mathrm{PPC} / \mathrm{E} 3$ when $1 \mathrm{kA}$ or less, else PPC/E 0" or " $1000 \mathrm{~A}$ fuses require $\mathrm{PPC} / \mathrm{E} 3$ when $1 \mathrm{kA}$ or less, else PPC/E 2", and are aimed at determining default arc flash $\mathrm{PPC} / \mathrm{E}$ category requirements for $4160 \mathrm{~V}$ applications. In the second table, for $480 \mathrm{~V}$ applications, notes such as "200A ETUs require PPC/E 4 when $1 \mathrm{kA}$ or less, else $\mathrm{PPC} / \mathrm{E} 2$. This is true regardless of the settings" or "1200A ETUs require PPC/E 4 if the instantaneous setting is higher than 4 or when $5 \mathrm{kA}$ or less, else PPC/E 2" are taken down for each device. These notes are required to determine default arc flash $\mathrm{PPC} / \mathrm{E}$ category requirements for $480 \mathrm{~V}$ applications.

TABLE 1 (only 2 devices shown)

\begin{tabular}{|c|c|c|c|c|c|c|}
\hline & \multicolumn{5}{|c|}{$\begin{array}{l}\text { 4160V PPC/E \& Boundary Results } \\
\text { a Given Short Circuit Level in kA }\end{array}$} & \multirow[t]{2}{*}{ Notes } \\
\hline Device & 1 & 5 & 15 & 30 & 40 & \\
\hline $\begin{array}{l}120 \mathrm{~A} \\
\text { Vac. Int. }\end{array}$ & $\begin{array}{l}\mathrm{PPC} \\
/ \mathrm{E} 0 \\
47 \\
\mathrm{~mm}\end{array}$ & $\begin{array}{l}\text { PPC } \\
/ \mathrm{E} 0 \\
270 \\
\mathrm{~mm}\end{array}$ & $\begin{array}{l}\text { PPC } \\
/ \mathrm{E} 0 \\
897 \\
\mathrm{~mm}\end{array}$ & $\begin{array}{l}\text { PPC } \\
/ \mathrm{E} 1 \\
1913 \\
\mathrm{~mm}\end{array}$ & $\begin{array}{l}\text { PPC } \\
/ \mathrm{E} 1 \\
2620 \\
\mathrm{~mm}\end{array}$ & $\mathrm{PPC} / \mathrm{E}=1$ \\
\hline $\begin{array}{l}200 \mathrm{~A} \\
\text { fuses }\end{array}$ & $\begin{array}{l}\mathrm{PPC} \\
/ \mathrm{E} 3 \\
7094 \\
\mathrm{~mm}\end{array}$ & $\begin{array}{l}\text { PPC } \\
/ \mathrm{E} 0 \\
754 \\
\mathrm{~mm}\end{array}$ & $\begin{array}{l}\text { PPC } \\
/ \mathrm{E} 0 \\
505 \\
\mathrm{~mm}\end{array}$ & $\begin{array}{l}\mathrm{PPC} \\
/ \mathrm{E} 0 \\
801 \\
\mathrm{~mm}\end{array}$ & $\begin{array}{l}\mathrm{PPC} \\
/ \mathrm{E} 0 \\
723 \\
\mathrm{~mm}\end{array}$ & $\begin{array}{l}\text { 200A fuses } \\
\text { require } \\
\text { PPC/E } 3 \\
\text { when } 1 \mathrm{kA} \text { or } \\
\text { less, else } \\
\mathrm{PPC} / \mathrm{E} 0\end{array}$ \\
\hline
\end{tabular}


TABLE 2 (only 2 devices shown)

\begin{tabular}{|c|c|c|c|c|c|c|}
\hline & \multicolumn{5}{|c|}{$\begin{array}{l}\text { 480V PPC/E \& Boundary Results @ } \\
\text { Given Short Circuit Level in kA }\end{array}$} & \multirow[t]{2}{*}{ Notes } \\
\hline Device & 1 & 5 & 15 & 30 & 40 & \\
\hline $\begin{array}{l}\text { 200AT } \\
\text { ETUs } \\
* *\end{array}$ & $\begin{array}{l}\text { PPE } \\
=2 \\
1060 \\
\mathrm{~mm}\end{array}$ & $\begin{array}{l}\text { PPE } \\
=0 \\
380 \\
\mathrm{~mm}\end{array}$ & $\begin{array}{l}\text { PPE } \\
=1 \\
706 \\
\mathrm{~mm}\end{array}$ & $\begin{array}{l}\mathrm{PPE} \\
=2 \\
1070 \\
\mathrm{~mm}\end{array}$ & $\begin{array}{l}\mathrm{PPE} \\
=2 \\
1276 \\
\mathrm{~mm}\end{array}$ & \multirow{4}{*}{$\begin{array}{l}200 \mathrm{~A} \\
\text { ETUs } \\
\text { require } \\
\text { PPE } 3 \\
\text { when } \\
1 \mathrm{kA} \text { or } \\
\text { less, } \\
\text { else } \\
\text { PPE } 2 \\
\text { This is } \\
\text { true } \\
\text { regardl } \\
\text { ess of } \\
\text { the } \\
\text { settings }\end{array}$} \\
\hline $\begin{array}{l}200 \mathrm{AT} \\
\mathrm{ETUs} \\
* * *\end{array}$ & $\begin{array}{l}\text { PPE } \\
=3 \\
1905 \\
\mathrm{~mm}\end{array}$ & $\begin{array}{l}\text { PPE } \\
=0 \\
380 \\
\mathrm{~mm}\end{array}$ & $\begin{array}{l}\text { PPE } \\
=1 \\
706 \\
\mathrm{~mm}\end{array}$ & $\begin{array}{l}\mathrm{PPE} \\
=2 \\
1070 \\
\mathrm{~mm}\end{array}$ & $\begin{array}{l}\mathrm{PPE} \\
=2 \\
1276 \\
\mathrm{~mm}\end{array}$ & \\
\hline $\begin{array}{l}200 \mathrm{AT} \\
\mathrm{ETUs} \\
* * * *\end{array}$ & $\begin{array}{l}\text { PPE } \\
=3 \\
1905 \\
\mathrm{~mm}\end{array}$ & $\begin{array}{l}\text { PPE } \\
=0 \\
380 \\
\mathrm{~mm}\end{array}$ & $\begin{array}{l}\text { PPE } \\
=1 \\
706 \\
\mathrm{~mm}\end{array}$ & $\begin{array}{l}\text { PPE } \\
=2 \\
1070 \\
\mathrm{~mm}\end{array}$ & $\begin{array}{l}\text { PPE } \\
=2 \\
1276 \\
\mathrm{~mm}\end{array}$ & \\
\hline $\begin{array}{l}200 \mathrm{AT} \\
\mathrm{ETUs} \\
* * * * *\end{array}$ & $\begin{array}{l}\text { PPE } \\
=2 \\
1359 \\
\mathrm{~mm}\end{array}$ & $\begin{array}{l}\mathrm{PPE} \\
=0 \\
380 \\
\mathrm{~mm}\end{array}$ & $\begin{array}{l}\text { PPE } \\
=1 \\
706 \\
\mathrm{~mm}\end{array}$ & $\begin{array}{l}\text { PPE } \\
=2 \\
1070 \\
\mathrm{~mm}\end{array}$ & $\begin{array}{l}\text { PPE } \\
=2 \\
1276 \\
\mathrm{~mm}\end{array}$ & \\
\hline $\begin{array}{l}\text { 500AT } \\
\mathrm{CBs}\end{array}$ & $\begin{array}{l}\text { PPE } \\
=3 \\
1905 \\
\mathrm{~mm}\end{array}$ & $\begin{array}{l}\mathrm{PPE} \\
=\mathrm{X} \\
5096 \\
\mathrm{~mm}\end{array}$ & $\begin{array}{l}\text { PPE } \\
=0 \\
448 \\
\mathrm{~mm}\end{array}$ & $\begin{array}{l}\text { PPE } \\
=1 \\
573 \\
\mathrm{~mm}\end{array}$ & $\begin{array}{l}\text { PPE } \\
=1 \\
674 \\
\mathrm{~mm}\end{array}$ & $\begin{array}{l}\text { 500A } \\
\text { CBs } \\
\text { require } \\
\text { PPE X } \\
\text { when } \\
5 \mathrm{kA} \text { or } \\
\text { less, } \\
\text { else } \\
\text { PPE 1 }\end{array}$ \\
\hline
\end{tabular}

*X signifies that the incident energy level is higher than 40 $\mathrm{cal} / \mathrm{cm}^{2}$

** All ETUs are modeled with STPU set at the highest setting, a STD of 0.3 and Instantaneous Value of 4.

*** All ETUs are modeled with STPU set at the highest setting, a STD of 0.3 and Instantaneous Value of 6.

**** All ETUs are modeled with STPU set at the highest setting, a STD of 0.3 and Instantaneous Value of 10 . *****All ETUs are modeled with STPU set at 4, a STD of 0.3 and the Instantaneous Value set at the highest setting.

\section{TRENDS FOR ARC FLASH BOUNDARY}

A set of devices was selected in the initial list of the sample study for the sole purpose of comparing $480 \mathrm{~V}$ applications to $4160 \mathrm{~V}$ applications, in terms of arc flash boundary. The reason some of these devices were selected for comparison only is because not every device is installed at both voltage levels at the sample site. A portion of the $480 \mathrm{~V}$ devices from the original list were tested at $4160 \mathrm{~V}$ to determine the differences in the results. All of the devices were computed at both voltages in the calculator and a table (see Table 3) was created to emphasize difference in boundary requirements. The table had each device listed smallest size to largest size, and gave a unique row for the $480 \mathrm{~V}$ device and the $4160 \mathrm{~V}$ device, yet near each other for easy comparison. Five columns were provided for each input fault current level $(1 \mathrm{kA}, 5 \mathrm{kA}$, etc.) and the table listed the worstcase $\mathrm{PPC} / \mathrm{E}$ and arc flash boundary on the given matrix. Notes were taken for each device, such as
" $1854 \mathrm{~mm}-927 \mathrm{~mm}=927 \mathrm{~mm} \quad(\mathrm{PPC} / \mathrm{E} \quad 1), \quad 3005 \mathrm{~mm}-$ $1276 \mathrm{~mm}=1729 \mathrm{~mm}(\mathrm{PPC} / \mathrm{E} 2)$ " which describe the worst-case differences between the $4160 \mathrm{~V}$ boundary and the $480 \mathrm{~V}$ boundary given worst-case conditions for a particular PPC/E level. These differences were used in determining the largest boundary disparity between $480 \mathrm{~V}$ and $4160 \mathrm{~V}$ applications for a given $\mathrm{PPC} / \mathrm{E}$ category. This table was also used in determining worst-case boundaries associated with various PPC/E levels at the $480 \mathrm{~V}$ level by placing the highest boundary associated with a PPC/E level in italics, regardless of the device type. According to the devices sampled the boundary gets increasingly higher according to the $\mathrm{PPC} / \mathrm{E}$ level, regardless of device type. However, the voltage seems to have a more significant impact.

TABLE 3 (only sample devices shown)

\begin{tabular}{|c|c|c|c|c|c|c|}
\hline & \multicolumn{5}{|c|}{$\begin{array}{l}\text { 4160V \& 480V for comparison only } \\
\text { PPC/E \& Boundary Results @ } \\
\text { Given Short Circuit Level in kA }\end{array}$} & \multirow[t]{2}{*}{ Notes } \\
\hline $\begin{array}{l}\text { Device } \\
* * * * * *\end{array}$ & 1 & 5 & 15 & 30 & 40 & \\
\hline $\begin{array}{l}125 \mathrm{AT} \\
\mathrm{CB} @ \\
4160 \mathrm{~V}\end{array}$ & $\begin{array}{l}\text { PPE } \\
=1 \\
1387 \\
\mathrm{~mm}\end{array}$ & $\begin{array}{l}\text { PPE } \\
=0 \\
113 \\
\mathrm{~mm}\end{array}$ & $\begin{array}{l}\text { PPE } \\
=0 \\
376 \\
\mathrm{~mm}\end{array}$ & $\begin{array}{l}\text { PPE } \\
=0 \\
801 \\
\mathrm{~mm}\end{array}$ & 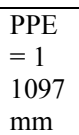 & \multirow{2}{*}{ 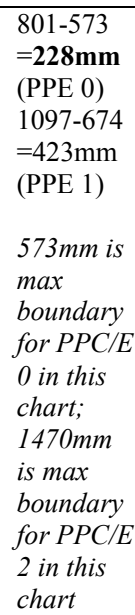 } \\
\hline $\begin{array}{l}125 \mathrm{AT} \\
\mathrm{CB} @ \\
480 \mathrm{~V}\end{array}$ & $\begin{array}{l}\text { PPE } \\
=2 \\
\mathbf{1 4 7 0} \\
\mathbf{~ m m}\end{array}$ & $\begin{array}{l}\text { PPE } \\
=0 \\
209 \\
\mathrm{~mm}\end{array}$ & $\begin{array}{l}\text { PPE } \\
=0 \\
388 \\
\mathrm{~mm}\end{array}$ & $\begin{array}{l}\text { PPE } \\
=0 \\
\mathbf{5 7 3} \\
\mathbf{~ m m}\end{array}$ & $\begin{array}{l}\text { PPE } \\
=1 \\
674 \\
\mathrm{~mm}\end{array}$ & \\
\hline $\begin{array}{l}\text { 200AT } \\
\text { ETU@ } \\
4160 \mathrm{~V}\end{array}$ & $\begin{array}{l}\text { PPE } \\
=0 \\
53 \\
\mathrm{~mm}\end{array}$ & $\begin{array}{l}\text { PPE } \\
=0 \\
310 \\
\mathrm{~mm}\end{array}$ & $\begin{array}{l}\text { PPE } \\
=1 \\
1030 \\
\mathrm{~mm}\end{array}$ & $\begin{array}{l}\text { PPE } \\
=1 \\
2195 \\
\mathrm{~mm}\end{array}$ & $\begin{array}{l}\text { PPE } \\
=1 \\
3005 \\
\mathrm{~mm}\end{array}$ & \multirow[t]{2}{*}{$\begin{array}{l}1030-706 \\
=324 \mathrm{~mm} \\
(\mathrm{PPE} 1)\end{array}$} \\
\hline $\begin{array}{l}\text { 200AT } \\
\text { ETU @ } \\
480 \mathrm{~V}\end{array}$ & $\begin{array}{l}\text { PPE } \\
=2 \\
1060 \\
\mathrm{~mm}\end{array}$ & $\begin{array}{l}\text { PPE } \\
=0 \\
380 \\
\mathrm{~mm}\end{array}$ & $\begin{array}{l}\text { PPE } \\
=1 \\
706 \\
\mathrm{~mm}\end{array}$ & $\begin{array}{l}\text { PPE } \\
=2 \\
1070 \\
\mathrm{~mm}\end{array}$ & $\begin{array}{l}\text { PPE } \\
=2 \\
1276 \\
\mathrm{~mm}\end{array}$ & \\
\hline $\begin{array}{l}500 \mathrm{AT} \\
\mathrm{CB} @ \\
4160 \mathrm{~V}\end{array}$ & $\begin{array}{l}\text { PPE } \\
=1 \\
2981 \\
\mathrm{~mm}\end{array}$ & $\begin{array}{l}\text { PPE } \\
=3 \\
8522 \\
\mathrm{~mm}\end{array}$ & $\begin{array}{l}\text { PPE } \\
=0 \\
248 \\
\mathrm{~mm}\end{array}$ & $\begin{array}{l}\text { PPE } \\
=0 \\
528 \\
\mathrm{~mm}\end{array}$ & $\begin{array}{l}\text { PPE } \\
=0 \\
723 \\
\mathrm{~mm}\end{array}$ & \multirow{2}{*}{$\begin{array}{l}\begin{array}{l}528-448 \\
=80 \mathrm{~mm}\end{array} \\
\text { (PPE 0) } \\
8522- \\
5096 \\
=3426 \mathrm{~mm} \\
(\mathrm{PPE} \\
3 / 4 / \mathrm{X})\end{array}$} \\
\hline $\begin{array}{l}500 \mathrm{AT} \\
\mathrm{CB} @ \\
480 \mathrm{~V}\end{array}$ & $\begin{array}{l}\text { PPE } \\
=3 \\
1905 \\
\mathrm{~mm}\end{array}$ & $\begin{array}{l}\text { PPE } \\
=X \\
5096 \\
\mathrm{~mm}\end{array}$ & $\begin{array}{l}\text { PPE } \\
=0 \\
303 \\
\mathrm{~mm}\end{array}$ & $\begin{array}{l}\text { PPE } \\
=0 \\
448 \\
\mathrm{~mm}\end{array}$ & $\begin{array}{l}\text { PPE } \\
=1 \\
527 \\
\mathrm{~mm}\end{array}$ & \\
\hline $\begin{array}{l}\text { 600AT } \\
\text { ETU@ } \\
4160 \mathrm{~V}\end{array}$ & $\begin{array}{l}\text { PPE } \\
=1 \\
2981 \\
\mathrm{~mm}\end{array}$ & $\begin{array}{l}\text { PPE } \\
=0 \\
191 \\
\mathrm{~mm}\end{array}$ & $\begin{array}{l}\text { PPE } \\
=0 \\
635 \\
\mathrm{~mm}\end{array}$ & $\begin{array}{l}\text { PPE } \\
=1 \\
1354 \\
\mathrm{~mm}\end{array}$ & $\begin{array}{l}\text { PPE } \\
=1 \\
1854 \\
\mathrm{~mm} \\
\end{array}$ & \multirow{2}{*}{ 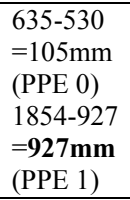 } \\
\hline $\begin{array}{l}600 \mathrm{AT} \\
\text { ETU @ }\end{array}$ & $\begin{array}{l}\text { PPE } \\
=3\end{array}$ & $\begin{array}{l}\text { PPE } \\
=0\end{array}$ & $\begin{array}{l}\text { PPE } \\
=0\end{array}$ & $\begin{array}{l}\text { PPE } \\
=1\end{array}$ & $\begin{array}{l}\text { PPE } \\
=1\end{array}$ & \\
\hline
\end{tabular}




\begin{tabular}{|c|c|c|c|c|c|c|}
\hline $480 \mathrm{~V}$ & $\begin{array}{l}1905 \\
\mathrm{~mm}\end{array}$ & $\begin{array}{l}286 \\
\mathrm{~mm}\end{array}$ & $\begin{array}{l}530 \\
\mathrm{~mm}\end{array}$ & $\begin{array}{l}783 \\
\mathrm{~mm}\end{array}$ & $\begin{array}{l}927 \\
\text { mm }\end{array}$ & $\begin{array}{l}927 m m \text { is } \\
\text { max } \\
\text { boundary } \\
\text { for PPC/E } \\
1 \text { in this } \\
\text { chart }\end{array}$ \\
\hline $\begin{array}{l}\text { 800AT } \\
\text { ETU @ } \\
4160 \mathrm{~V}\end{array}$ & $\begin{array}{l}\text { PPE } \\
=1 \\
2981 \\
\mathrm{~mm}\end{array}$ & $\begin{array}{l}\text { PPE } \\
=0 \\
310 \\
\mathrm{~mm}\end{array}$ & $\begin{array}{l}\text { PPE } \\
=1 \\
1030 \\
\mathrm{~mm}\end{array}$ & $\begin{array}{l}\text { PPE } \\
=1 \\
2195 \\
\mathrm{~mm}\end{array}$ & $\begin{array}{l}\text { PPE } \\
=1 \\
3005 \\
\mathrm{~mm}\end{array}$ & $\begin{array}{l}1030- \\
706= \\
324 \mathrm{~mm} \\
\text { (PPE 1) }\end{array}$ \\
\hline $\begin{array}{l}\text { 800AT } \\
\text { ETU @ } \\
480 \mathrm{~V}\end{array}$ & $\begin{array}{l}\text { PPE } \\
=3 \\
1905 \\
\mathrm{~mm} \\
\end{array}$ & $\begin{array}{l}\text { PPE } \\
=3 \\
2844 \\
\mathrm{~mm}\end{array}$ & $\begin{array}{l}\text { PPE } \\
=1 \\
706 \\
\mathrm{~mm}\end{array}$ & $\begin{array}{l}\text { PPE } \\
=2 \\
1070 \\
\mathrm{~mm} \\
\end{array}$ & $\begin{array}{l}\text { PPE } \\
=2 \\
1276 \\
\mathrm{~mm}\end{array}$ & \\
\hline $\begin{array}{l}1200 \\
\text { AT } \\
\text { ETU@ } \\
4160 \mathrm{~V}\end{array}$ & $\begin{array}{l}\text { PPE } \\
=1 \\
2981 \\
\mathrm{~mm}\end{array}$ & $\begin{array}{l}\text { PPE } \\
=3 \\
8565 \\
\mathrm{~mm}\end{array}$ & $\begin{array}{l}\text { PPE } \\
=1 \\
1030 \\
\mathrm{~mm}\end{array}$ & $\begin{array}{l}\text { PPE } \\
=1 \\
2195 \\
\mathrm{~mm}\end{array}$ & $\begin{array}{l}\text { PPE } \\
=1 \\
3005 \\
\mathrm{~mm}\end{array}$ & $\begin{array}{l}1030- \\
706= \\
324 \mathrm{~mm} \\
\text { (PPE 1) }\end{array}$ \\
\hline $\begin{array}{l}1200 \\
\text { AT } \\
\text { ETU @ } \\
480 V\end{array}$ & $\begin{array}{l}\text { PPE } \\
=3 \\
1905 \\
\mathrm{~mm}\end{array}$ & $\begin{array}{l}\text { PPE } \\
=X \\
5096 \\
\mathrm{~mm}\end{array}$ & $\begin{array}{l}\text { PPE } \\
=1 \\
706 \\
\mathrm{~mm}\end{array}$ & $\begin{array}{l}\text { PPE } \\
=2 \\
1070 \\
\mathrm{~mm}\end{array}$ & $\begin{array}{l}\text { PPE } \\
=2 \\
1276 \\
\mathrm{~mm}\end{array}$ & $\begin{array}{l}8565- \\
5096=\mathbf{3 4 6} \\
\mathbf{9 m m} \\
(\mathrm{PPE} \\
3 / 4 / \mathrm{X})\end{array}$ \\
\hline $\begin{array}{l}2000 \\
\text { AT } \\
\text { ETU @ } \\
4160 \mathrm{~V}\end{array}$ & $\begin{array}{l}\text { PPE } \\
=1 \\
2981 \\
\mathrm{~mm}\end{array}$ & $\begin{array}{l}\text { PPE } \\
=3 \\
1728 \\
5 \\
\mathrm{~mm} \\
\end{array}$ & $\begin{array}{l}\text { PPE } \\
=1 \\
1030 \\
\mathrm{~mm}\end{array}$ & $\begin{array}{l}\text { PPE } \\
=1 \\
2195 \\
\mathrm{~mm}\end{array}$ & $\begin{array}{l}\text { PPE } \\
=1 \\
3005 \\
\mathrm{~mm}\end{array}$ & $\begin{array}{l}\mathrm{n} / \mathrm{a}=\text { will } \\
\text { not work } \\
\text { on } \\
\text { energized }\end{array}$ \\
\hline $\begin{array}{l}2000 \\
\text { AT } \\
\text { ETU @ } \\
480 V\end{array}$ & $\begin{array}{l}\text { PPE } \\
=3 \\
1905 \\
\mathrm{~mm}\end{array}$ & $\begin{array}{l}\text { PPE } \\
=X \\
5096 \\
\mathrm{~mm}\end{array}$ & $\begin{array}{l}\text { PPE } \\
=X \\
5549 \\
\mathrm{~mm}\end{array}$ & $\begin{array}{l}\text { PPE } \\
=3 \\
4712 \\
\mathrm{~mm}\end{array}$ & $\begin{array}{l}\text { PPE } \\
=4 \\
\mathbf{5 6 1 8} \\
\mathbf{m m}\end{array}$ & $\begin{array}{l}5618 \mathrm{~mm} \\
\text { is max } \\
\text { boundary } \\
\text { for PPC/E } \\
4 \text { in this } \\
\text { chart }\end{array}$ \\
\hline $\begin{array}{l}2500 \\
\text { AT } \\
\text { ETU @ } \\
4160 \mathrm{~V}\end{array}$ & $\begin{array}{l}\text { PPE } \\
=1 \\
2981 \\
\mathrm{~mm}\end{array}$ & $\begin{array}{l}\text { PPE } \\
=3 \\
1728 \\
5 \\
\mathrm{~mm}\end{array}$ & $\begin{array}{l}\text { PPE } \\
=1 \\
1030 \\
\mathrm{~mm}\end{array}$ & $\begin{array}{l}\text { PPE } \\
=1 \\
2195 \\
\mathrm{~mm}\end{array}$ & $\begin{array}{l}\text { PPE } \\
=1 \\
3005 \\
\mathrm{~mm}\end{array}$ & $\begin{array}{l}\mathrm{n} / \mathrm{a}=\text { will } \\
\text { not work } \\
\text { on } \\
\text { energized }\end{array}$ \\
\hline
\end{tabular}

*X signifies that the incident energy level is higher than 40 $\mathrm{cal} / \mathrm{cm}^{2}$

****** All ETUs are modeled with STPU set at the highest setting, a STD of 0.3 and Instantaneous Value of 4.

\section{INCIDENT ENERGY LEVEL}

Each PPC/E category has an associated arc rating expressed in $\mathrm{cal} / \mathrm{cm}^{2}$. Incident energy is measured in $\mathrm{cal} / \mathrm{cm}^{2}$. After the incident energy level at a particular device at a particular location on the system is calculated by IEEE 1584-2002, the corresponding $\mathrm{PPC} / \mathrm{E}$ category can be determined for the work. The category corresponds with certain clothing and equipment requirements outlined by NFPA 70E. The range of incident energy levels is defined by the NFPA 70E-2004 as follows:

Incident energy from 0 to $1.2 \mathrm{cal} / \mathrm{cm}^{2}$ for PPC/E 0
Incident energy above 1.2 to $4 \mathrm{cal} / \mathrm{cm}^{2}$ for PPC/E 1 Incident energy above 4 to $8 \mathrm{cal} / \mathrm{cm}^{2}$ for PPC/E 2 Incident energy above 8 to $25 \mathrm{cal} / \mathrm{cm}^{2}$ for PPC/E 3 Incident energy above 25 to $40 \mathrm{cal} / \mathrm{cm}^{2}$ for PPC/E 4 The clothing at the sample site is rated at a maximum energy level in each category. The outcome of each device tested in the bounding study was within the ranges noted above. Since PPC/E categories are determined for a range of devices under certain conditions in the study, the incident energy is not exact, but within the range given above. This means that first the PPC/E category may be determined for a given set of devices under certain conditions and then the maximum incident energy level for that category may be specified for the work. This approach is conservative and realistic because it gives an exaggerated incident energy level, but maintains the PPC/E requirements for the particular task. This requires the site or plant to have equipment and clothing that is rated at a maximum for each PPC/E category.

\section{SHORT CIRCUIT CLASSIFICATION}

One of the main components of arc flash energy is the fault level available at the device. As discussed before, the arcing current is a percentage of the fault level and should ideally be high enough to trip the device in the instantaneous region and low enough to prevent a large arc. If a study has not been developed to show the short circuit levels at each low and medium voltage bus at your plant or site, you will need to identify if an arc flash hazard may occur due to the low or high arcing currents using another approach. In order to do this, you must identify if you have potential for low arcing currents, high arcing currents or both.

The next step is to establish a fault level at the source(s) (e.g., substation, incoming transformer). A combination of downstream cable sizes, cable lengths, transformer sizes, transformer impedances, generation and motor capability contributes to the final fault level at a given location. The aim of the bounding study is to establish whether the fault level is dangerously high or dangerously low at the device, based on its location within the plant or site.

When dealing with the possibility of low arcing currents the parameters of cables and transformers become essential. Usually, assumptions can be made concerning cable size. For example, in the sample study there was a concern for low arcing currents in the range of $1 \mathrm{kA}$ to $5 \mathrm{kA}$, which trends indicated that devices $400 \mathrm{~A}$ and larger at $480 \mathrm{~V}$ were problematic in this range. This size device is usually sized for a load of $300 \mathrm{~A}$ or more and usually requires $500 \mathrm{kcmil}$ cable. This same methodology can be duplicated to 
select a cable size for study purposes to be used at other voltages, such as $4160 \mathrm{~V}$. When the voltage is above $5 \mathrm{kV}$, say $15 \mathrm{kV}$, the cable length should be determined by reviewing the system. Usually a particular size is used on the main utility distribution line and can be utilized for study purposes. The next step is to determine how to approach the bounding study from this point forward. The sample site had several sources (12.47kV substations) and low and medium voltage devices installed in facilities spread over a wide-area. As a result, the study determined a maximum distance, from each source to the $12.47 \mathrm{kV}$ $480 \mathrm{~V}$ transformer and then determined a maximum distance from each transformer to the device. In order to stay above $5 \mathrm{kA}$ when the source bus at the main substation is $1 \mathrm{kA}$ the distances are limited to 10 miles from substation to transformer at $12.47 \mathrm{kV}$ and 400 feet from transformer to device at $480 \mathrm{~V}$. Similarly, all $4160 \mathrm{~V}$ runs from the upstream transformer to the device are limited to 2000 feet or less. Additional cases were run to determine when the source provided less then $1 \mathrm{kA}$ to see if the short circuit provided to the transformer with the low and medium voltage on the secondary was high enough to provide the same $2000 \mathrm{ft}(4160 \mathrm{~V})$ and 400 feet $(480 \mathrm{~V})$ recommendations mentioned above. Also, areas more than 10 miles from the main substation were analyzed in the same manner. In completing a bounding study for a plant, it is best to identify one source bus to several main locations within the plant and then identify the maximum length for your $4160 \mathrm{~V}$ and $480 \mathrm{~V}$ distances from that point on. Ultimately, the characteristics of a site will determine the approach.

The transformers, considered only nodes in the cable study, must be evaluated separately. For the sample study transformer impedances dictated by IEEE Std 141-1986 were used. Given an infinite bus it was determined how various transformer sizes affected short circuit availability. For instance, a $150 \mathrm{kVA}$ transformer allows $7.2 \mathrm{kA}$ fault current through to the $480 \mathrm{~V}$ side. After reviewing the full range of transformer sizes, the only problematic configuration at $480 \mathrm{~V}$, given typical transformer impedance, is for very small transformers (smaller than 150kVA) and devices larger than 400A. This configuration is not realistic at $480 \mathrm{~V}$ so there becomes no actual limitation on transformer size at the sample site at $480 \mathrm{~V}$. These limitations, in combination with the cable length limitations can be used to identify hazards at a location. Looking upstream from the device one can determine the source, distance from the source and upstream transformer size to decide if an extreme arc flash hazard exists.
If your concern is instead for high arcing currents, you will want to consider transformer size and motor contribution. For instance, when working near a large motor load the fault current is high, and therefore, arcing current is high enough to create a potential hazard. Often, you will also need to identify sources of generation which contribute to high fault levels. These locations also need to be identified as extremely dangerous. Considering the short circuit level on the secondary side of a transformer given an infinite bus may also be useful, since large transformers allow for a potentially high fault current and small transformers limit the fault on secondary busses. Again, the characteristics of your site or plant will determine the exact approach for your study.

\section{RESULTS}

At $240 \mathrm{~V}$ and below, engineering judgment is required for determining the arc flash requirements. The NFPA 70E table recommends either a PPC/E of 0 or 1 for all tasks, unless the expected short circuit is higher than $25 \mathrm{kA}$ with a fault clearing time of 2 cycles. The IEEE 1584 recommends analysis when the device under consideration involves at least one $125 \mathrm{kVA}$ or larger low-impedance transformer in its immediate power supply. As a result we considered the NFPA $70 \mathrm{E}$ tables at $240 \mathrm{~V}$ and below, except when the transformer upstream from the device was $125 \mathrm{kVA}$ or larger. In these situations a $\mathrm{PPC} / \mathrm{E}$ value of 2 was recommended. This is conservative, since many of the transformers on the sample site are not low-impedance.

Category $3 \mathrm{PPC} / \mathrm{E}$ was eliminated as an option for $\mathrm{PPC} / \mathrm{E}$ since the sample site only invested in category $4 \mathrm{PPC} / \mathrm{E}$ clothing. As a result, all tasks requiring category $3 \mathrm{PPC} / \mathrm{E}$ default to category $4 \mathrm{PPC} / \mathrm{E}$ at the sample site. This is commonly done by industry since both category 3 and category $4 \mathrm{PPC} / \mathrm{E}$ requires an arc flash suit or several layers of uncomfortable clothing. This approach is cost-effective since the clothing is very expensive to purchase.

The size and type of device was one of the main determining factors governing the hazard level associated with arc flash. Typically smaller devices are less hazardous to work around since they react faster under arcing conditions. By definition the size of a device could be one of many attributes: trip size, frame size, plug size, etc. For arc flash applications, the tripping characteristics are the only features, in terms of size, that affect the analysis. For example, an ETU's plug size and trip setting are critical to the outcome, not the frame size. It is important to develop categories by the size and type of device, and for each of these categories to consider a range of 
conditions in order to assign the appropriate $\mathrm{PPC} / \mathrm{E}$ level.

In regards to the LSI type ETUs, it was ascertained that if the instantaneous value was set above a certain value, the short-time pickup setting would cause the curve to change considerably, especially when the instantaneous setting was set high. These settings were determined to be the most important settings since the long-time pickup and long-time delay were assumed high. Given the device list created for the sample site, two major breakpoints were determine for $480 \mathrm{~V}$ applications; the hazard increased when the instantaneous was above 4 and the hazard increased when the instantaneous was set higher than 6 or "off". The short-time pickup setting breakpoints were enveloped in our recommendations because the majority of the disturbances in the short-time pickup setting were above the instantaneous setting of 6 .

As mentioned previously, the method of assigning arc flash PPC/E by task in NFPA can be misleading. As a result, only the tasks which are most cautioned about in the table are considered an additional hazard by the arc flash bounding study. For a few tasks, it is recommended that either the highest level of caution be observed, or for smaller devices an additional level of caution be used.

Since relays were not considered in the sample study but are usually installed at medium voltages, equipment that is controlled by this type of device at $4160 \mathrm{~V}$ had an unpredicted outcome. The worst-case scenario, or a PPC/E category of 4 was assigned for all work associated with the relay controlled device at the sample site.

As discussed before, the default value of 4.0 feet in NFPA $70 \mathrm{E}$ is not valid or accurate under all conditions. As a result the IEEE 1584 was used to determine the maximum boundary required for $480 \mathrm{~V}$ applications, given the device list chosen for the sample site and the trends shown in Table 3. The outcome, listed below, is based on devices modeled at the sample site and should only be regarded as an example only.

$\begin{array}{cc}\text { Assigned PPC/E Category } & \text { Boundary @ 480V } \\ 0 & 2 \text { feet } \\ 1 & 3 \text { feet } \\ 2 & 5 \text { feet } \\ 4 & 19 \text { feet }\end{array}$

The deviation between these boundaries and the boundary requirements at $4160 \mathrm{~V}$ were also considered in the bounding study. Given the $480 \mathrm{~V}$ equipment list determined for the sample site and the $4160 \mathrm{~V}$ comparison of these devices, the largest disparity was found to be 1 foot for PPC/E level 0,3 feet for PPC/E level 1, 10 feet for PPC/E level 2 and 12 feet at PPC/E level 4. All of these values were determined by comparing the $480 \mathrm{~V}$ and $4160 \mathrm{~V}$

devices in Table 3 at similar short circuit levels which also had time-current characteristics that were similar in nature. Unless working on a very small device a category 0 is not recommended at $4160 \mathrm{~V}$. The outcome at $4160 \mathrm{~V}$, listed below, is based on devices modeled at the sample site and should only be regarded as an example only.

Assigned PPC/E Category

$\begin{array}{ll}0 & 3 \text { feet } \\ 1 & 6 \text { feet } \\ 2 & 15 \text { feet } \\ 4 & 25 \text { feet* }\end{array}$

*Most of the $4160 \mathrm{~V}$ devices actually have faster clearing times than the devices chosen for comparison purposes which are common only at $480 \mathrm{~V}$. So the disparities discovered by Table 3 are conservative. The arc flash boundary disparity determined by Table 3 for PPC/E 4 was determined to be 12 feet, however, only 6 feet was used resulting in a $4160 \mathrm{~V}$ Arc Flash Boundary of 25 feet. This is considered acceptable since the arc flash boundaries determined in Table 1 and Table 3 for $4160 \mathrm{~V}$ devices do not exceed 25 feet in any case.

Cable distance and transformer size may be limited to certain values to prevent hazardous arcing conditions at the sample site. When the values are exceeded higher PPC/E is recommended. The values are largely dependent on your system's characteristics and require full consideration so good results may be obtained.

\section{CONCLUSIONS}

The findings from the study must be implemented in the field so qualified electrical workers can work as safely as possible. One way to implement the findings of an arc flash study is to create a table that outlines the requirements, assigns a default $\mathrm{PPC} / \mathrm{E}$ category according to the device worked on and for a given set of conditions, and then finds the corresponding boundary for that level of PPC/E. The $\mathrm{PPC} / \mathrm{E}$ should be rated for the maximum incident energy level mentioned in Section VII. These tables can either be used by a cognizant engineer or field worker to label equipment on the system or the tables can be developed for electrical workers to use on the job. This second approach is especially advantageous for temporary installations. Tables were developed for the sample site based on the results and trends observed in the arc flash bounding study for the sample site. One of these sample tables is illustrated in Appendix A and was developed for field personnel at the sample site. This chart is an example only, since it is based on devices, assumptions, and input data associated with the sample site.

In the future, engineering personnel should make it a standard process to set equipment to clear as fast as possible given that the requirements are met for proper coordination. This is primarily in the short- 
time and instantaneous region of the time-current curve of devices. This strategy will increase the overall number of devices on your system that will trip effectively under arcing conditions and lower the arc flash hazard associated with the device.

The bounding study should be revisited on a regular basis, possibly annually, to determine if the calculation still maintains its bounding properties. The device list should be revisited to verify if it still encompasses the range of time-current characteristics of equipment onsite. As technology changes, new devices are sometimes introduced to the system, which may need arc flash consideration. Also, the short circuit range selected reflects system design, including motor contribution, generation and cable length and size and transformer data. If there are major changes to these items, the range selected for the study may need revised.

Another reason the bounding study should be revisited is to include developments in arc flash technology. Since this field is emerging, it is expected that more testing will alter the equations and recommendations of the IEEE 1584 and NFPA 70E. These equations and recommendations, in addition to OSHA requirements, should be taken into account.

\section{ACKNOWLEDGEMENTS}

The authors wish to thank Ken Jones, Vice President of PDA Design Services for his input and assistance on several arc flash issues, which consequently inspired this publication. The authors would also like to thank Larry Kelley, Senior Electrical Engineer at Bechtel's Savannah River Site, for his technical review of the sample bounding calculation and Ed Laner, Principal Engineer at Bechtel Nevada, who supported the initiative to produce a sample bounding arc flash study. The authors are also grateful to Bruce McClung, current IEEE Fellow and former Union Carbide Corporate Fellow, who provided valuable comments in reviewing the paper.

\section{REFERENCES}

[1] IEEE Std 1584-2002, "Guide for Arc Flash Hazard Calculations", The Institute of Electrical and Electronics Engineers, Inc., New York, NY 10016.

[2] NFPA 70E, "Standard for Electrical Safety in the Workplace”, 2004 Edition, National Fire Protection Association Inc., Quincy, MA 02169.

[3] Presentation "Arc Flash Hazard Calculations: Why? How? What's Next?" - Daniel Doan, Dupont, Engineering Safety Conference 2004.

[4] NFPA 70, "National Electric Code", 2002
Edition, National Fire Protection Association, Inc., Quincy, MA 02169

[5] IEEE Std. 141-1986, "IEEE Recommended Practice for Electric Power Distribution for Industrial Plants", Copyright(C 1986 by the Institute of Electrical and Electronics Engineers, Inc.

\section{VITA}

Michelle Palizzi (IEEE Member '05) received a Bachelors of Science degree in Electrical Engineering from Virginia Tech. Michelle has had the opportunity to work on many aspects of power engineering design during her career. She currently performs system studies for Bechtel Nevada, one of the main contractors of the Nevada Test Site. She also has experience in utility distribution planning and design, nuclear plant design and power plant construction. Her most recent achievements have been the preparation of a sample arc flash bounding study and attaining membership on the IEEE 1584 Working Group committee.

Sunil Kabra received a Masters of Science degree in Electrical Engineering from Virginia Tech. He obtained his Bachelors degree in Electrical Engineering at IIT Roorkee (formerly University of Roorkee). He is currently employed as an Electrical Engineer at Bechtel Power Corporation where he performs a variety of systems design calculations. He also has experience in design of fossil and nuclear plant distribution systems, emergency diesel and UPS systems, and protection \& metering systems. He is a licensed Professional Engineer.

This report was prepared as an account of work sponsored by an agency of the U.S. Government. Neither the U.S. Government nor any agency thereof, nor any of their employees, nor any of their contractors, subcontractors or their employees, makes any warranty, express or implied, or assumes any legal liability or responsibility for the accuracy, completeness, or any third party's use or the results of such use of any information, apparatus, product, or process disclosed, or represents that its use would not infringe privately owned rights. Reference herein to any specific commercial product, process, or service by trade name, trademark, manufacturer, or otherwise, does not necessarily constitute or imply its endorsement, recommendation, or favoring by the U.S. Government or any agency thereof or its contractors or subcontractors. The views and opinions of authors expressed herein do not necessarily state or reflect those of the U.S. Government or any agency thereof.

This work was supported by the U.S. Department of Energy, National Nuclear Security Administration Nevada Operations Office, under Contract No. AC08-96NV11718. 


\section{Appendix A: 480V AC Arc Flash PPE Table for Area $X$ where the fault current at the main sub \\ is $1 \mathrm{kA} \&$ no medium voltage exists in the run}

Start with Condition

1 and continue

to Condition 6.

The FIRST

Condition that

is true gives the selected row.

Also, start left and move right to check each column description. The FIRST true

statement gives the selected column.

\begin{tabular}{|c|c|c|c|c|c|c|c|c|c|c|}
\hline & & & 2 & 2 & $\varrho$ & & & 단 & & 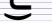 \\
\hline Condition 1 & $X^{*}$ & 4 & 4 & 4 & 4 & 4 & 4 & 4 & 4 & 4 \\
\hline Condition 2 & $X^{*}$ & 4 & 4 & 4 & 4 & 4 & 4 & 4 & 4 & 2 \\
\hline Condition 3 & $X^{*}$ & 4 & 4 & 4 & 4 & 4 & 4 & 4 & 2 & 1 \\
\hline Condition 4 & $X^{*}$ & 4 & 4 & 4 & 4 & 4 & 4 & 2 & 2 & 1 \\
\hline Condition 5 & $X^{*}$ & & 4 & 4 & 2 & & & & & \\
\hline Condition 6 & $\mathbf{X}^{*}$ & & 4 & 2 & 1 & & & & & \\
\hline None of the above & 4 & 4 & 2 & 2 & 1 & 2 & 1 & 1 & 1 & 0 \\
\hline
\end{tabular}

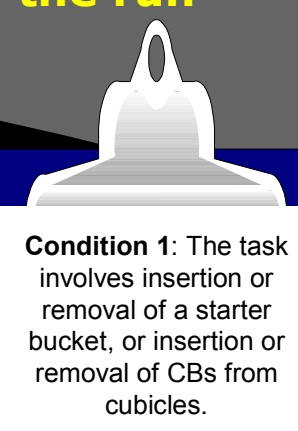

Condition 2: The distance from the main substation is more than 10 miles.

Condition 3: The distance or cable length from the device to the main transformer exceeds 400 feet.

Condition 4: The nearest upstream transformer is $150 \mathrm{kVA}$ or smaller.

\section{Condition 5: The} Instantaneous setting on the electronic trip unit is set higher than 6 or is OFF.

Condition 6: The Instantaneous setting on the electronic trip unit is set higher than 4

\section{${ }^{*} \mathrm{X}=$ Do not work on or near the device when energized.}

The above chart is recommended for all work "on" or "near" 480V energized devices. This includes working on or near exposed $480 \mathrm{~V}$ parts of the device. This includes tasks such as working on control circuits near exposed energized parts, opening hinged covers to exposed parts, removing bolted covers to exposed energized parts and switching with or without covers.

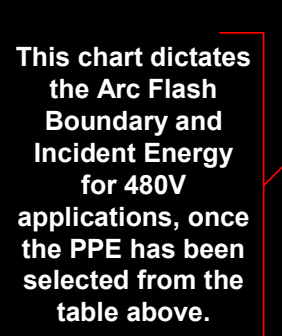

\begin{tabular}{|c|c|c|c|}
\hline $\begin{array}{c}\text { Selected Arc } \\
\text { Flash PPE }\end{array}$ & $\begin{array}{c}\text { Required Arc } \\
\text { Flash Boundary }\end{array}$ & $\begin{array}{c}\text { Assigned Incident } \\
\text { Energy Level }\end{array}$ & \begin{tabular}{c} 
Clothing Description** \\
\hline 0
\end{tabular} \\
\hline 1 & 2 feet & $1.2 \mathrm{cal} / \mathrm{cm}^{2}$ & Long-sleeve shirt \& pants \\
\hline 2 & 6 feet & $8.0 \mathrm{cal} / \mathrm{cm}^{2}$ & FR shirt \& pants \\
\hline 4 & 20 feet & $40.0 \mathrm{cal} / \mathrm{cm}^{2}$ & $\begin{array}{c}\text { FR shirt \& pants + Flash hood (or } 8 \\
\text { cal face shield) + Leather gloves + } \\
\text { Ear plugs }\end{array}$ \\
\hline All PPE classes require safety glasses and hard hat. A t-shirt is required under all FR and Arc Flash Clothing. \\
\hline
\end{tabular}

